\title{
Bovine Serum Albumin Protein Detection by a Removable SPR Chip Combined with a Specific MIP Receptor
}

\author{
Francesco Arcadio ${ }^{1}$, Luigi Zeni ${ }^{1}$,, Chiara Perri ${ }^{1}$, Girolamo D'Agostino ${ }^{2}$, Giudo Chiaretti ${ }^{2}$, Giovanni Porto ${ }^{2}$, \\ Aldo Minardo ${ }^{1}\left(\mathbb{D}\right.$ and Nunzio Cennamo ${ }^{1, *(\mathbb{D})}$ \\ 1 Department of Engineering, University of Campania Luigi Vanvitelli, Via Roma n.29, 81031 Aversa, Italy; \\ francesco.arcadio@unicampania.it (F.A.); luigi.zeni@unicampania.it (L.Z.); chiara.perri@unicampania.it (C.P.); \\ aldo.minardo@unicampania.it (A.M.) \\ 2 Moresense Srl, Filarete Foundation, Viale Ortles 22/4, 20139 Milan, Italy; g.dagostino@moresense.tech (G.D.); \\ g.chiaretti@moresense.tech (G.C.); g.porto@moresense.tech (G.P.) \\ * Correspondence: nunzio.cennamo@unicampania.it; Tel.: +39-081-5010367
}

check for

updates

Citation: Arcadio, F.; Zeni, L.; Perri, C.; D'Agostino, G.; Chiaretti, G.;

Porto, G.; Minardo, A.; Cennamo, N. Bovine Serum Albumin Protein Detection by a Removable SPR Chip Combined with a Specific MIP Receptor. Chemosensors 2021, 9, 218. https://doi.org/10.3390/

chemosensors 9080218

Academic Editor: Xiaobing Zhang

Received: 8 June 2021

Accepted: 8 August 2021

Published: 11 August 2021

Publisher's Note: MDPI stays neutral with regard to jurisdictional claims in published maps and institutional affiliations.

Copyright: (c) 2021 by the authors. Licensee MDPI, Basel, Switzerland. This article is an open access article distributed under the terms and conditions of the Creative Commons Attribution (CC BY) license (https:/ / creativecommons.org/licenses/by/ $4.0 /)$.

\begin{abstract}
Nowadays, the development of simple, fast, and low-cost selective sensors to detect substances of interest is of great importance in several application fields. Among this kind of sensors, those based on surface plasmon resonance (SPR) represent a promising category, since they are highly sensitive, versatile, and label-free. In this work, an SPR probe, based on a poly(methyl methacrylate) (PMMA) slab waveguide covered by a gold nanofilm, combined with a specific molecularly imprinted polymer (MIP) receptor for bovine serum albumin (BSA) protein, has been realized and experimentally characterized. The obtained experimental results have shown a limit of detection (LOD) equal to about $8.5 \times 10^{-9} \mathrm{M}$. This value is smaller than the one achieved by another SPR probe, based on a D-shaped plastic optical fiber (POF), functionalized with the same MIP receptor; more specifically, the obtained LOD was reduced by about three orders of magnitude with respect to the POF configuration. Moreover, concerning the D-shaped POF configuration, no manufacturing process is present in the proposed sensor configuration. In addition, fibers are used only to connect the simple sensor chip with a light source and a detector, promoting a bio-chemical sensing approach based on disposable, low-cost, and removable chips.
\end{abstract}

Keywords: surface plasmon resonance (SPR); molecularly imprinted polymers (MIPs); optical sensors; bovine serum albumin (BSA) protein

\section{Introduction}

Among several sensing techniques, optical sensors based on surface plasmon resonance (SPR) represent a promising category, since they are very sensitive, versatile and do not require labelling procedures [1-4]. The SPR phenomenon is based on the interaction of light and free electrons in a noble metal nanofilm in contact with a dielectric medium. In biochemical sensing applications, the sensor surface can be covered with a specific receptor layer. Therefore, when an analyte interacts with the receptor layer in contact with the SPR sensor's metallic nanofilm, a variation of its refractive index occurs. The SPR probe detects this refractive index variation, because the SPR conditions change.

Several types of SPR sensors are prism-based (Kretschmann configuration) [5-8], which need bulky and expensive experimental setups, making it hard for the realization of miniaturized devices for on-field measurements as well as point-of-care (POC) diagnostics devices. Several SPR sensors have been implemented to overcome this issue by taking advantage of optical fibers, both silica glass and plastic ones [9-14].

SPR sensors based on intrinsic optical fibers have been presented in a variety of forms and configurations by exploiting, for instance, unclad fibers, tapered fibers, side-polished fibers, and U-bent fibers [15-19]. Furthermore, by coupling these configurations with 
various types of receptors, multiple applications have been developed so far, bringing together experts from many disciplines such as chemistry and physics with medical sciences. Moreover, recently, extrinsic optical fiber sensors have been presented. In extrinsic fiber sensors, optical fibers are used only to connect a sensing region with a light source and a detector. Up to now, intrinsic and extrinsic fiber-optic SPR sensors have been realized for sensing in environmental, security, industrial, biomedical, and biochemical sectors, detecting from small chemical compounds to more complex biological molecules such as proteins [20-24].

Recently, SPR fiber-optic sensors have been realized by exploiting plastic optical fibers (POFs) because of their high flexibility, ease of handling, high numerical apertures, large diameters, and the fact that plastic can sustain lower bend radii than glass. For instance, SPR sensors in D-shaped POFs [17] have been successfully exploited in our research group, as the flat part lends itself very well to be coupled with different molecular recognition elements (MREs), either biological receptors (antibodies, enzymes, aptamers, etc.) or chemical receptors (nanomaterials, molecularly imprinted polymers (MIPs), etc.) [25-27]. In particular, MIPs have shown significant advantages over biological receptors, as they are easy, fast and quite cheap to prepare and characterized by a greater resistance to temperature and $\mathrm{pH}$, making them much more suitable for on-field applications.

SPR D-shaped POF probes coupled with MIPs have been exploited, realizing several applications ranging from detecting environmental pollutants and industrial analytes to biological applications, such as the detection of the SARS-CoV-2 virus $[28,29]$. However, Dshaped POF platforms can create several difficulties in large-scale production, for example, irreproducibility issues due to the polishing process.

A possible alternative to SPR D-shaped POF sensor configurations can be represented by SPR platforms based on slab optical waveguides, as shown by Taguchi et al. [30]. Along this line, Cennamo et al. have presented a low-cost SPR platform based on a poly(methyl methacrylate) (PMMA) slab waveguide with a gold nanofilm on the top, coupled with a source and a detector exploiting two POFs and a particular holder, designed to excite the plasmonic resonance at the gold-dielectric interface [31]. More specifically, Cennamo et al. in [31] have demonstrated that the SPR in a PMMA slab waveguide presents similar performances to those obtained by SPR sensors based on D-shaped POFs [17]. Moreover, the SPR sensor in a polymer slab waveguide offers various benefits in terms of easy manufacturing of the sensor and reproducibility due to the absence of polishing procedure and the possibility of an easy replacement of the chip [31,32]. More specifically, this innovative plasmonic sensor has been described as a refractive-index sensor in [31] and as a chemical sensor to detect furfural in [32]. The plasmonic chip is tightly held by a holder specifically designed to assure a reproducible positioning of the slab. The method for launching the light in the slab, which happens through an air trench, is a distinguishing characteristic of the suggested experimental setup. It permits a large number of modes to pass through the slab waveguide, some of which can activate the SPR in the refractive index range under consideration. The designed holder is connected to a white light source and a spectrometer by two POFs [31,32].

In this work, an SPR platform based on a PMMA slab waveguide [31] has been combined with an MIP receptor specific for the bovine serum albumin (BSA) protein detection. Although epitope imprinting is well used, we have decided to use a different imprinting strategy in this work. We aimed to make imprinting of the entire protein molecule.

This novel BSA sensor has been realized and characterized. Finally, a comparison analysis between the developed BSA sensor and other BSA sensors has been presented. In this comparative analysis, it's interesting to compare the proposed sensor with two of our plasmonic POF platforms coupled with the same MIP receptor for BSA. In particular, we have compared the presented sensor with two sensors based on different plasmonic platforms, i.e., one similar to the one proposed in the present study, in terms of sensitivity, and the other one which was highly sensitive based on gold nanogratings. The experimental 
results presented have demonstrated that the BSA sensor proposed here could be a trade-off between them with several advantages.

\section{Materials and Methods}

\subsection{SPR Sensor Based on a PMMA Slab Waveguide}

An SPR sensor based on a PMMA slab waveguide has been implemented as indicated in [31]. In particular, an initial sample consisted of a $10 \mathrm{~mm} \times 10 \mathrm{~mm} \times 0.5 \mathrm{~mm}$ PMMA chip (GoodFellow, Huntingdon, UK) that was used as a slab waveguide. To obtain the plasmonic sensor, the unique necessary production step consisted of a $60 \mathrm{~nm}$-thick gold film deposited on the slab surface by a sputter coater machine (BalTec SCD 500, Schalksmühle, Germany). The deposition process was split into three steps (20 $\mathrm{nm}$ per step), each with a current of $60 \mathrm{~mA}$, a working pressure of $0.05 \mathrm{mbar}$, and a deposition time of $35 \mathrm{~s}$, to guarantee a low-temperature process $[17,31]$.

\subsection{Reagents}

N-tert-butylacrylamide (TBAm) (CAS 107-58-4), 2-hydroxyethyl methacrylate (HEMA), acrylamide (Aam) (CAS 79-06-1), N, $\mathrm{N}^{\prime}$-methylene bisacrylamide (BIS) (CAS 110-26-9), 2-Hydroxyethyl methacrylate (CAS 868-77-9), N,N, $\mathrm{N}^{\prime}, \mathrm{N}^{\prime}$-tetramethylethylenediamine (TEMED) (CAS 110-18-9), ammonium persulfate (APS) (CAS 7727-54-0), sodium dodecyl sulfate (SDS) (CAS 151-21-3), and phosphate buffer (PB) solution (1.0 M) were from Sigma-Aldrich (Darmstadt, Germa-ny) and used without any further purification. All other chemicals were of analytical reagent grade. The solvent was Milli-Q water.

Human serum albumin (BSA) (CAS 9048-46-8) and trypsin (CAS 9002-07-7) were from Sigma-Aldrich (Darmstadt, Germany).

\subsection{MIP Receptor for BSA Protein Detection}

A nanometric layer of a synthetic receptor for BSA was grown on a gold surface. In order to do that, a recently developed MIP synthesis strategy for proteins was used [28]. The preparation is summarized below.

The first step involved the modification of the gold surface of an optical transducer with an allyl thiol. In particular, the gold surface of the transducer was modified by immersing it in a $10 \%(v / v)$ solution of allyl thiol in $80 \%(v / v)$ ethanol solution and $10 \%$ $(v / v)$ water for $12 \mathrm{~h}$. Subsequently, the platform was washed with Milli-Q water (flushing $3 \mathrm{~mL} 5$ times). A self-assembled monolayer with a terminal allyl group was formed through this process and subsequently, was used to bind the MIP receptor covalently.

The monomer mixture was prepared by adding Aam, TBAm, and HEMA at 1:0.5:0.6 molar ratio in $15 \mathrm{mM} \mathrm{PB}$ with $\mathrm{pH}$ of 7.4. The final concentration of BIS in the monomeric mix was $0.19 \mathrm{M}$. The pre-polymeric mixture was dispersed by sonication (sonic bath model VWR USC200T) for $10 \mathrm{~min}$ and bubbled with $\mathrm{N}_{2}$ for $30 \mathrm{~min}$ at room temperature. The template (BSA protein) was added to the pre-polymeric mixture to the final concentration of $1 \mu \mathrm{M}$. Then, APS ( $w / v: 0.08 \%)$ and TEMED ( $w / v: 0.06 \%)$ were added. About $2 \mu \mathrm{L}$ of the pre-polymeric mixture were dropped over the sensing region, and polymerization was allowed for $15 \mathrm{~min}$ at room temperature, after which the reticulation process was stopped by washing the sensor surface with Milli-Q water. Finally, the template was removed by incubating trypsin $\left(4.2 \times 10^{-8} \mathrm{M}\right)$ for $2 \mathrm{~h}$ at room temperature on the sensor surface and then by a washing step with a $5 \%(w / v)$ SDS solution.

\subsection{Experimental Setup}

In order to test the plasmonic platform based on a PMMA slab waveguide, of which the schematic cross-section is reported in Figure 1a, we have used a simple and low-cost experimental setup, outlined in Figure 1b [31,32]. In particular, it consisted of a white light source, two POF patches (total diameter: $1 \mathrm{~mm}$ ), a metallic holder, and a spectrometer. A light source (model HL-2000-LL, produced by Ocean Optics, Dunedin, FL, USA) emitted wavelengths in a spectral range between $360 \mathrm{~nm}$ and $1700 \mathrm{~nm}$. The light was launched in 
a POF patch from the white light source, and then it was coupled to the slab waveguide through a specific trench in the metallic holder. Another POF patch, kept at 90 degrees with respect to the other one, was used to collect the transmitted light and send it to a spectrometer (model FLAME-S-VIS-NIR-ES, produced by Ocean Optics, Dunedin, FL, USA), which showed a detection range between $350 \mathrm{~nm}$ and $1023 \mathrm{~nm}$.

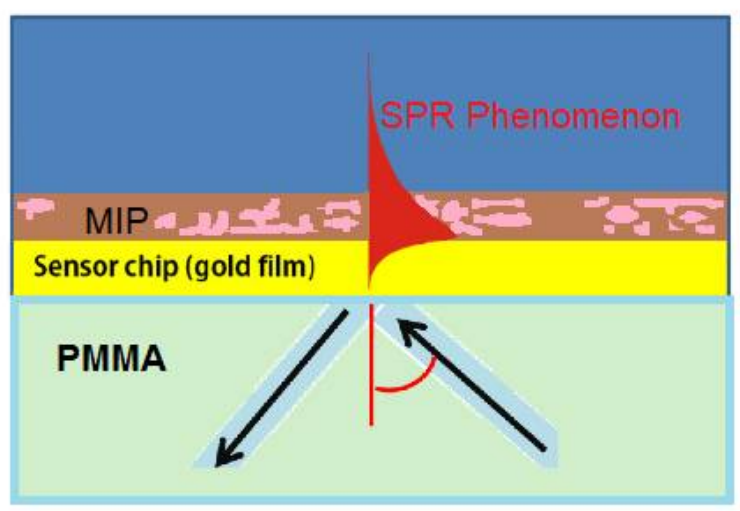

(a)

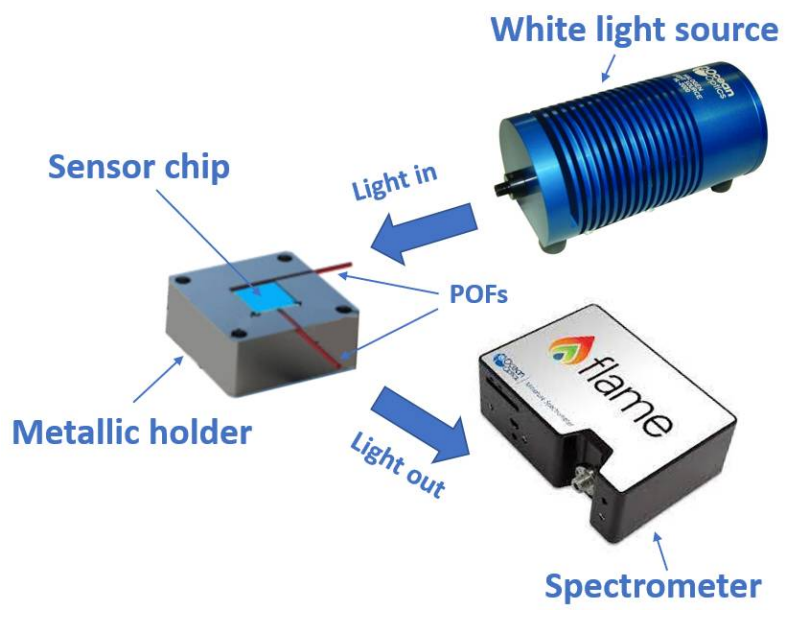

(b)

Figure 1. (a) Outline of the sensor chip cross-section. (b) Experimental setup.

\subsection{Data Acquisition Protocol}

The flat surface of the sensor makes it possible to perform measurements in a drop simply deposited over the sensing surface. The sensor chip was fixed in a custom holder, which was purposely designed to keep the sensing surface in a horizontal position, and a reference spectrum was acquired (with air as the surrounding medium). A BSA sample drop $(50 \mu \mathrm{L})$ was then deposited over the flat part of the SPR sensor covered by the MIP and equilibrated for $5 \mathrm{~min}$. After this step, the surface was rinsed with a buffer solution, so the refractive index variation related to the matrix was eliminated, the so-called "bulk effect". Finally, the SPR spectrum was acquired and analyzed to extract the resonance wavelength shift via Matlab software.

\subsection{Binding Experiments}

In order to perform binding tests, we prepared BSA solutions at different concentrations in $\mathrm{PB}(\mathrm{pH}=7.4)$ starting from a lyophilized protein. In particular, we tested the following BSA concentrations: $10^{-10} \mathrm{M}, 10^{-9} \mathrm{M}, 10^{-8} \mathrm{M}, 10^{-7} \mathrm{M}, 10^{-6} \mathrm{M}$, and $10^{-5} \mathrm{M}$. 


\section{Results and Discussion}

Figure 2 shows the SPR transmitted spectra, which were normalized to the spectrum acquired with air as the surrounding medium (reference spectrum) before and after the MIP deposition process and acquired with a blank solution (i.e., buffer without an analyte) as bulk. In the presence of the same bulk medium, before and after the MIP deposition, a red shift of about $10 \mathrm{~nm}$ can be observed in the SPR transmission spectrum. This shift indicated an increment of the refractive index at the gold surface, confirming the formation of a receptor layer.

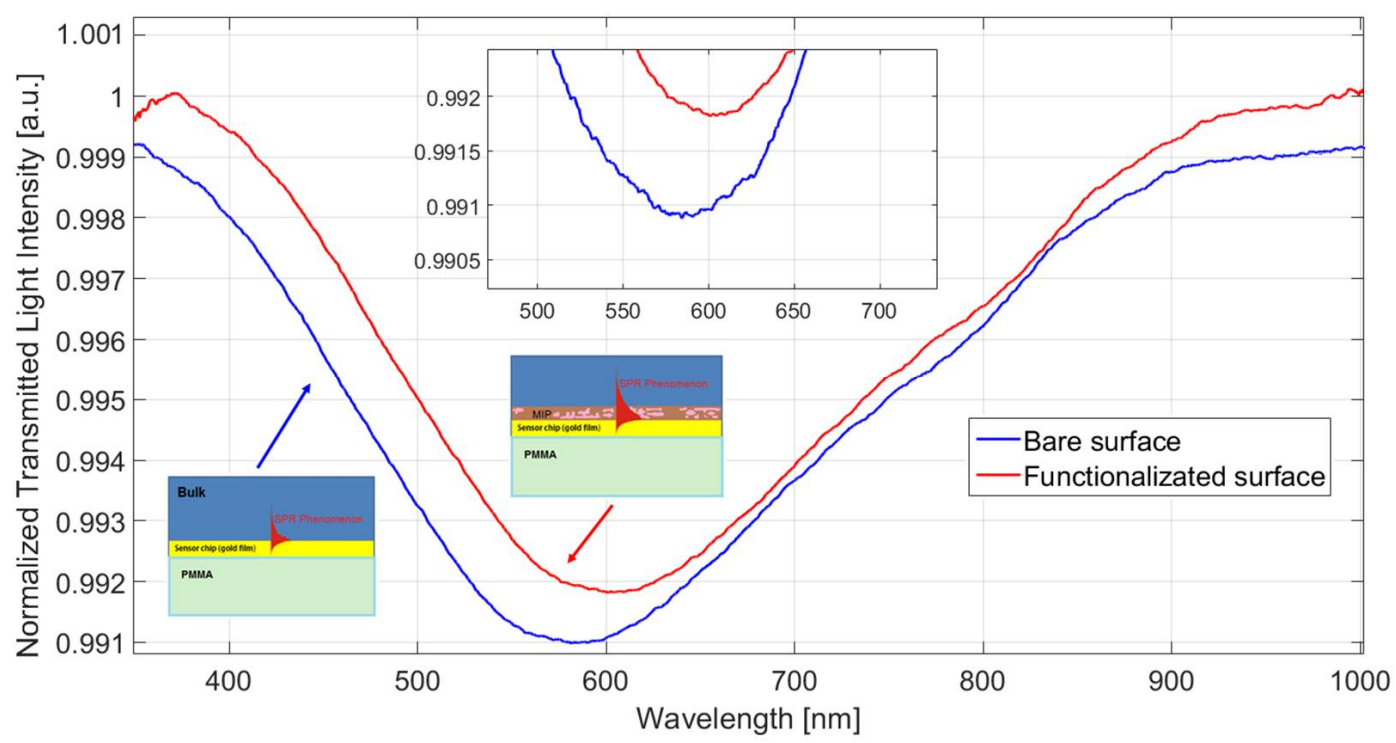

Figure 2. Normalized surface plasmon resonance (SPR) spectra, acquired in a buffer solution as bulk, obtained before and after the functionalization procedure.

Figure 3 reports the normalized SPR transmission spectra for different BSA concentrations ranging from 0 to $10^{-5} \mathrm{M}$. It is clear seen that when the BSA protein concentration increased, the resonance wavelength $(\lambda)$ increased (red shift).

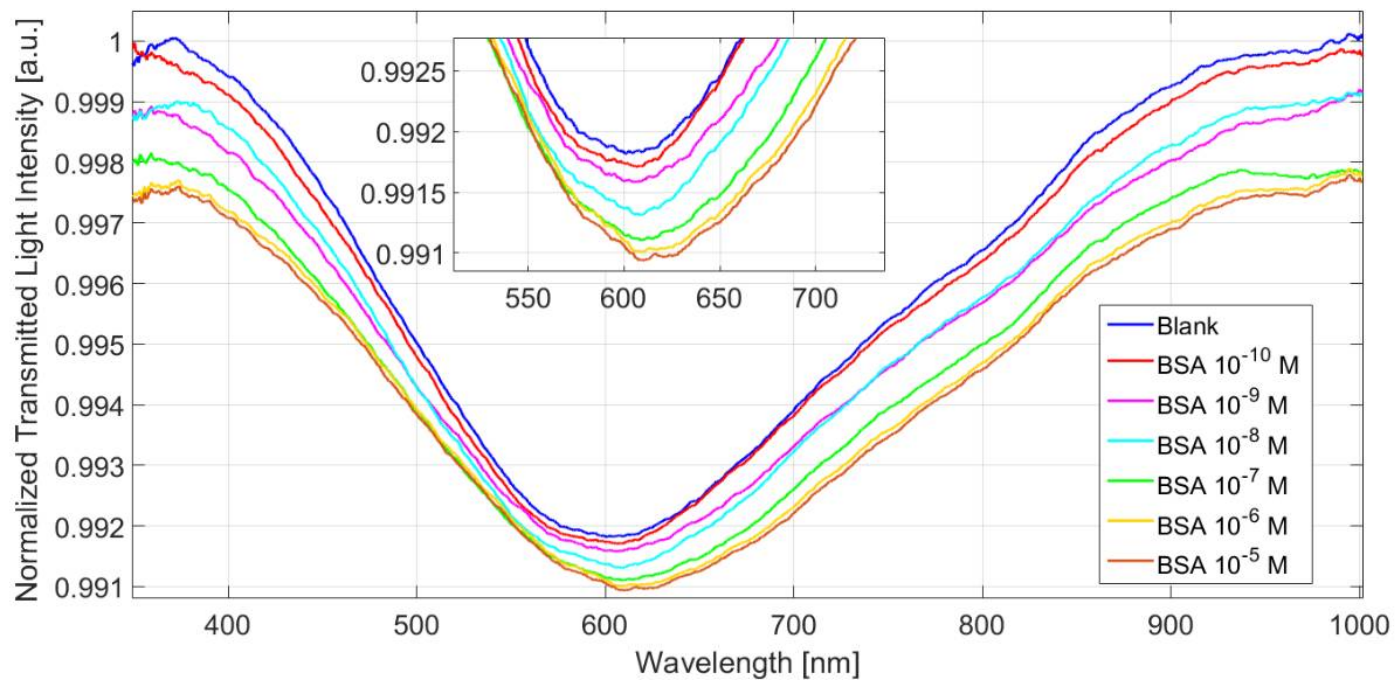

Figure 3. Normalized SPR transmitted spectra at varying bovine serum albumin (BSA) protein concentrations $\left(0-10^{-5} \mathrm{M}\right)$. Inset: zoom of the resonance wavelength area. 
In Figure 4, the resonance wavelength variation $(\Delta \lambda)$ with respect to the blank (solution without an analyte) is shown, along with the Hill fitting of the experimental data and the error bars in a semi-log scale. The experimental measurements were repeated three times for each sample, and the maximum error (equal to $0.2 \mathrm{~nm}$ ) was considered the error bar. The Hill equation used to fit the experimental data was reported as following:

$$
\Delta \lambda_{\mathrm{c}}=\lambda_{\mathrm{c}}-\lambda_{0}=\lambda_{0}+\left(\lambda_{\max }-\lambda_{0}\right) \cdot\left(\mathrm{c}^{n} /\left(\mathrm{K}^{n}+\mathrm{c}^{n}\right)\right),
$$

where $\mathrm{c}$ is the analyte concentration, $\lambda_{\mathrm{c}}$ is the resonance wavelength at concentration $\mathrm{c}, \lambda_{0}$ is the resonance wavelength at zero concentration (blank), $\lambda_{\max }$ is the saturation value, and $n$ and $\mathrm{K}$ are the Hill constants.

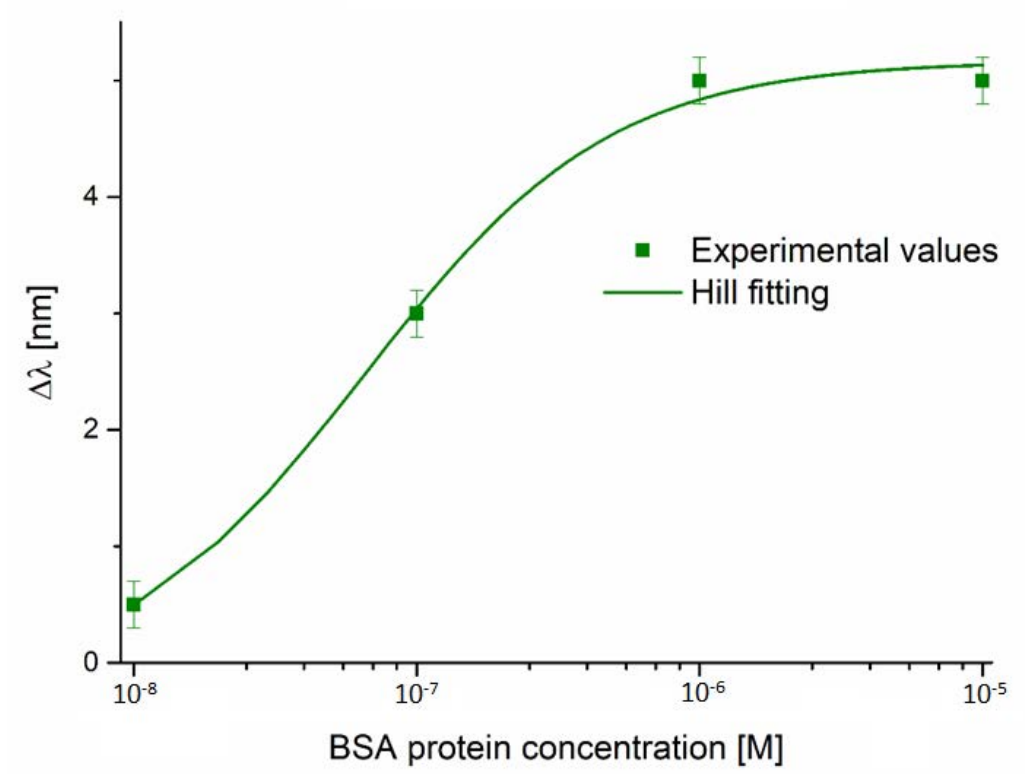

Figure 4. Resonance wavelength variation $(\Delta \lambda)$ with respect to the blank versus the concentration of BSA protein, with the Hill fitting of the experimental values and the error bars, in a semi-log scale.

Table 1 reports the parameters relative to Equation (1) for the analyzed configuration. In particular, when considering $n=1$ (in this case, the Hill equation is the same as the Langmuir equation) and low concentrations (i.e., c $\ll K)$, Equation (1) is a linear function, and the slope $\left(\left(\lambda_{\max }-\lambda_{0}\right) / \mathrm{K}\right)$ is called sensitivity at low concentrations. By considering the linear behavior at low BSA concentrations, the latter is used to calculate the limit of detection (LOD), defined as the ratio between two times the standard deviation of the blank (standard error of $\lambda_{0}$ reported in Table 1) and the sensitivity at low concentrations. We used the same LOD definition adopted in $[28,33,34]$ to compare the obtained performances with those of SPR D-shaped POF sensors and those of plasmonic nanograting-based POF sensors, both functionalized with the same MIP receptor for BSA. We have also presented a characterization of the used MIP (in terms of selectivity, stability, etc.) in our previous work [28]. Therefore, in this work, we did not report these aspects.

Table 1. Hill parameters relative to Equation (1) for BSA detection.

\begin{tabular}{ccccccccc}
\hline \multicolumn{2}{c}{$\lambda_{\mathbf{0}}(\mathbf{n m})$} & \multicolumn{2}{c}{$\lambda_{\max }(\mathbf{n m})$} & K (M) & $n$ & Statistics \\
\hline Value & $\begin{array}{c}\text { Standard } \\
\text { error } \\
\text { (stand. err.) }\end{array}$ & Value & Stand. err. & Value & Stand. err. & Value & $\begin{array}{c}\text { Reduced } \\
\text { chi-square }\end{array}$ & $\begin{array}{c}\text { Adj. } \\
\text { R-square }\end{array}$ \\
\hline-0.22 & 0.35 & 5.17 & 0.17 & $6.52 \times 10^{-8}$ & $1.72 \times 10^{-8}$ & 1 & 1.14 & 0.99 \\
\hline
\end{tabular}


Table 2 reports the chemical parameters relative to the BSA detection for the analyzed configuration. As reported in Table 3, the proposed SPR sensor based on a PMMA slab waveguide has shown a minor LOD value compared to SPR D-shaped POFs probes [28] and a major LOD value if compared to plasmonic nanograting-based POF sensor configurations $[33,34]$, combined with the same MIP receptor.

Table 2. Chemical parameters relative to the BSA detection.

\begin{tabular}{cccc}
\hline Configuration & Parameter & \\
\hline $\begin{array}{c}\text { BSA sensor based on SPR } \\
\text { probe in a PMMA slab } \\
\text { waveguide }\end{array}$ & $\begin{array}{c}\text { Sensitivity at low } \\
\text { concentrations (nm/M) }\end{array}$ & Limit of detection (LOD) (M) & $\left.\mathrm{Kaff}^{\prime}=1 / \mathrm{K}^{(\mathrm{M}}{ }^{-1}\right)$ \\
\cline { 2 - 4 } & $8.27 \times 10^{7}$ & $8.5 \times 10^{-9}$ & $1.53 \times 10^{7}$ \\
\hline
\end{tabular}

Table 3. Comparative analysis for several BSA sensors.

\begin{tabular}{|c|c|c|c|}
\hline Configuration & LOD & BSA Detection Range & Reference \\
\hline SPR in a PMMA slab waveguide & $8.5 \mathrm{nM}$ & $8.5 \mathrm{nM}-1 \mu \mathrm{M}$ & This work \\
\hline Gold nanograting on a PMMA substrate & $37 \mathrm{pM}$ & $37 \mathrm{pM}-100 \mathrm{nM}$ & [33] \\
\hline SPR D-shaped POFs & $0.37 \mu \mathrm{M}$ & $0.37 \mu \mathrm{M}-6.5 \mu \mathrm{M}$ & [28] \\
\hline GNG-based longitudinal (blue-shift resonance) & $23 \mathrm{pM}$ & 23 pM-10 nM & [34] \\
\hline GNG-based longitudinal (red-shift resonance) & $0.54 \mu \mathrm{M}$ & $0.54 \mu \mathrm{M}-10 \mu \mathrm{M}$ & [34] \\
\hline GNG-based orthogonal (blue-shift resonance) & $42 \mathrm{pM}$ & $42 \mathrm{pM}-10 \mathrm{nM}$ & [34] \\
\hline Fluorescence sensor & $10 \mathrm{nM}$ & $0.01 \mu \mathrm{M}-2 \mu \mathrm{M}$ & {$[35]$} \\
\hline $\begin{array}{l}\text { Aggregation-induced emission biosensor } \\
\text { coupled with graphene-oxide }\end{array}$ & $0.4 \mu \mathrm{M}$ & $0.4 \mu \mathrm{M}-1.5 \mu \mathrm{M}$ & [36] \\
\hline SPR-MoS2 optical fiber & $4.36 \mathrm{nM}$ & $4.36 \mathrm{nM}-750 \mathrm{nM}$ & [37] \\
\hline LSPR based on bimetallic nanoparticles & $0.15 \mathrm{pM}$ & $0.15 \mathrm{pM}-15 \mathrm{pM}$ & [38] \\
\hline Fiber-optic SPR & $5.8 \mathrm{fM}$ & $5.8 \mathrm{fM}-5 \mathrm{pM}$ & [39] \\
\hline SPR Kretschmann configuration & $0.3 \mu \mathrm{M}$ & $0.3 \mu \mathrm{M}-120 \mu \mathrm{M}$ & {$[40]$} \\
\hline
\end{tabular}

A comparative analysis for BSA sensors regarding the LOD and the detection range which was obtained by exploiting different sensing approaches, has been summarized in Table 3.

\section{Conclusions}

We have tested a plasmonic chemical sensor based on a PMMA slab waveguide combined with an MIP receptor specific for BSA protein detection. The results obtained, in terms of LODs (equal to about $8.5 \times 10^{-9} \mathrm{M}$ ), have demonstrated the advantages of the proposed approach. The performances of the proposed chemosensor have also been compared with another two plasmonic probes functionalized with the same MIP receptor (obtaining performances that could be considered a trade-off between them) and with other BSA sensors.

The main advantages of using this plasmonic platform regarding the SPR D-shaped POF probe are a simpler fabrication, a sensing approach which is simple to use and based on a disposable and removable sensor chip, and a better repeatability of large-scale production, because no polishing process is needed. Moreover, the used PMMA slab waveguide is also suitable to realize a sensor array by using more POFs in outputs and depositing different receptor layers accordingly.

Although the BSA sensor proposed here showed poorer performance compared with the BSA plasmonic nanograting sensor, we could work on the proposed sensing approach to further improve its performances by changing different parameters, such as the characteristic of the PMMA slab waveguide. 
Author Contributions: Conceptualization, F.A., L.Z., G.D. and N.C.; methodology, F.A., A.M., G.C., C.P., L.Z., G.D. and N.C.; validation, F.A., A.M., G.C., C.P., L.Z., G.D., G.P. and N.C.; formal analysis, F.A., A.M., G.C., C.P., L.Z., G.D., G.P. and N.C.; investigation, F.A., A.M., G.C., C.P., L.Z., G.D., G.P. and N.C.; resources, N.C., G.P. and L.Z.; data curation, F.A., A.M., G.C., C.P., L.Z., G.D., G.P. and N.C.; writing-original draft preparation, F.A., A.M., G.C., C.P., L.Z., G.D., G.P. and N.C.; writing-review and editing, F.A., A.M., G.C., C.P., L.Z., G.D., G.P. and N.C.; supervision, N.C. and L.Z. All authors have read and agreed to the published version of the manuscript.

Funding: This research received no external funding.

Institutional Review Board Statement: Not applicable.

Informed Consent Statement: Not applicable.

Data Availability Statement: The data is available on reasonable request from the corresponding author.

Acknowledgments: This work was supported by the VALERE program of the University of Campania “Luigi Vanvitelli" (Italy), CAMPANIA project.

Conflicts of Interest: The authors declare no conflict of interest.

\section{References}

1. Homola, J.; Yee, S.S.; Gauglitz, G. Surface plasmon resonance sensors: Review. Sens. Actuators B Chem. Sens. 1999, 54, 3-15. [CrossRef]

2. Nguyen, H.H.; Park, J.; Kang, S.; Kim, M. Surface Plasmon Resonance: A Versatile Technique for Biosensor Applications. Sensors 2015, 15, 10481-10510. [CrossRef]

3. Guo, X. Surface plasmon resonance based biosensor technique: A review. J. Biophotonics 2012, 5, 483-501. [CrossRef]

4. Hoa, X.D.; Kirk, A.G.; Tabrizian, M. Towards integrated and sensitive surface plasmon resonance biosensors: A review of recent progress. Biosens. Bioelectron. 2007, 23, 151-160. [CrossRef] [PubMed]

5. Luo, W.; Wang, R.; Li, H.; Kou, J.; Zeng, X.; Huang, H.; Hu, X.; Huang, W. Simultaneous measurement of refractive index and temperature for prism-based surface plasmon resonance sensors. Opt. Express 2019, 27, 576-589. [CrossRef] [PubMed]

6. Jha, R.; Sharma, A.K. High-performance sensor based on surface plasmon resonance with chalcogenide prism and aluminum for detection in infrared. Opt. Lett. 2009, 34, 749-751. [CrossRef]

7. Maurya, J.B.; Prajapati, Y.K. A comparative study of different metal and prism in the surface plasmon resonance biosensor having MoS2-graphene. Opt. Quant. Electron. 2016, 48, 280. [CrossRef]

8. Bolduc, O.R.; Live, L.S.; Masson, J.-F. High-resolution surface plasmon resonance sensors based on a dove prism. Talanta 2009, 77, 1680-1687. [CrossRef]

9. Sharma, A.K.; Jha, R.; Gupta, B.D. Fiber-Optic Sensors Based on Surface Plasmon Resonance: A Comprehensive Review. IEEE Sens. J. 2007, 7, 1118-1129. [CrossRef]

10. Monfared, Y.E. Overview of recent advances in the design of plasmonic fiber-optic biosensors. Biosensors 2020, 10, 77. [CrossRef]

11. Zhao, Y.; Tong, R.-j.; Xia, F.; Peng, Y. Current status of optical fiber biosensor based on surface plasmon resonance. Biosens. Bioelectron. 2019, 142, 111505. [CrossRef] [PubMed]

12. Martínez-Hernández, M.E.; Rivero, P.J.; Goicoechea, J.; Arregui, F.J. Trends in the Implementation of Advanced Plasmonic Materials in Optical Fiber Sensors (2010-2020). Chemosensors 2021, 9, 64. [CrossRef]

13. Zhao, Y.; Deng, Z.-q.; Li, J. Photonic crystal fiber based surface plasmon resonance chemical sensors. Sens. Actuators B Chem. 2014, 202, 557-567. [CrossRef]

14. Klantsataya, E.; Jia, P.; Ebendorff-Heidepriem, H.; Monro, T.M.; François, A. Plasmonic Fiber Optic Refractometric Sensors: From Conventional Architectures to Recent Design Trends. Sensors 2017, 17, 12. [CrossRef] [PubMed]

15. Kant, R.; Gupta, B.D. Fiber-Optic SPR Based Acetylcholine Biosensor Using Enzyme Functionalized Ta2O5 Nanoflakes for Alzheimer's Disease Diagnosis. J. Lightwave Technol. 2018, 36, 4018-4024. [CrossRef]

16. Luo, W.; Li, X.; Meng, J.; Wang, Y.; Hong, X. Surface Plasmon Resonance Sensor Based on Side-Polished D-Shaped Photonic Crystal Fiber With Split Cladding Air Holes. IEEE Trans. Instrum. Meas. 2021, 70, 1-11.

17. Cennamo, N.; Massarotti, D.; Conte, L.; Zeni, L. Low Cost Sensors Based on SPR in a Plastic Optical Fiber for Biosensor Implementation. Sensors 2011, 11, 11752-11760. [CrossRef]

18. Zhang, C.; Li, Z.; Jiang, S.Z.; Li, C.H.; Xu, S.C.; Yu, J.; Li, Z.; Wang, M.H.; Liu, A.H.; Man, B.Y. U-bent fiber optic SPR sensor based on graphene/AgNPs. Sens. Actuators B Chem. 2017, 251, 127-133. [CrossRef]

19. Cennamo, N.; Arcadio, F.; Minardo, A.; Montemurro, D.; Zeni, L. Experimental Characterization of Plasmonic Sensors Based on Lab-Built Tapered Plastic Optical Fibers. Appl. Sci. 2020, 10, 4389. [CrossRef]

20. Tabassum, R.; Gupta, B.D. Fiber optic manganese ions sensor using SPR and nanocomposite of ZnO-polypyrrole. Sens. Actuators $B$ Chem. 2015, 220, 903-909. [CrossRef]

21. Si, Y.; Lao, J.; Zhang, X.; Liu, Y.; Cai, S.; González-Vila, Á.; Li, K.; Huang, Y.; Yuan, Y.; Caucheteur, C.; et al. Electrochemical Plasmonic Fiber-optic Sensors for Ultra-Sensitive Heavy Metal Detection. J. Lightwave Technol. 2019, 37, 3495-3502. [CrossRef] 
22. Cennamo, N.; D’Agostino, G.; Porto, G.; Biasiolo, A.; Perri, C.; Arcadio, F.; Zeni, L. A Molecularly Imprinted Polymer on a Plasmonic Plastic Optical Fiber to Detect Perfluorinated Compounds in Water. Sensors 2018, 18, 1836. [CrossRef] [PubMed]

23. Wang, W.; Mai, Z.; Chen, Y.; Wang, J.; Li, L.; Su, Q.; Li, X.; Hong, X. A label-free fiber optic SPR biosensor for specific detection of C-reactive protein. Sci. Rep. 2017, 7, 16904. [CrossRef] [PubMed]

24. Sun, J.; Jiang, S.; Xu, J.; Li, Z.; Li, C.; Jing, Y.; Zhao, X.; Pan, J.; Zhang, C.; Man, B. Sensitive and selective surface plasmon resonance sensor employing a gold-supported graphene composite film/D-shaped fiber for dopamine detection. J. Phys. D Appl. Phys. J. 2019, 52, 195402. [CrossRef]

25. Cennamo, N.; Pasquardini, L.; Arcadio, F.; Vanzetti, L.E.; Bossi, A.M.; Zeni, L. D-shaped plastic optical fibre aptasensor for fast thrombin detection in nanomolar range. Sci. Rep. 2019, 9, 18740. [CrossRef]

26. Cennamo, N.; Zeni, L.; Ricca, E.; Isticato, R.; Marzullo, V.R.; Capo, A.; Staiano, M.; D'Auria, S.; Varriale, A. Detection of naphthalene in sea-water by a label-free plasmonic optical fiber biosensor. Talanta 2019, 194, 289-297. [CrossRef]

27. Cennamo, N.; D'Agostino, G.; Galatus, R.; Bibbò, L.; Pesavento, M.; Zeni, L. Sensors based on surface plasmon resonance in a plastic optical fiber for the detection of trinitrotoluene. Sens. Actuators B Chem. 2013, 188, 221-226. [CrossRef]

28. Cennamo, N.; D’Agostino, G.; Perri, C.; Arcadio, F.; Chiaretti, G.; Parisio, E.M.; Camarlinghi, G.; Vettori, C.; Di Marzo, F.; Cennamo, R.; et al. Proof of Concept for a Quick and Highly Sensitive On-Site Detection of SARS-CoV-2 by Plasmonic Optical Fibers and Molecularly Imprinted Polymers. Sensors 2021, 21, 1681. [CrossRef]

29. Cennamo, N.; Pesavento, M.; Zeni, L. A review on simple and highly sensitive plastic optical fiber probes for bio-chemical sensing. Sens. Actuators B Chem. 2021, 331, 129393. [CrossRef]

30. Taguchi, Y.; Takano, E.; Takeuchi, T. SPR Sensing of Bisphenol A Using Molecularly Imprinted Nanoparticles Immobilized on Slab Optical Waveguide with Consecutive Parallel Au and Ag Deposition Bands Coexistent with Bisphenol A-Immobilized Au Nanoparticles. Langmuir 2012, 28, 7083-7087. [CrossRef]

31. Cennamo, N.; Mattiello, F.; Zeni, L. Slab Waveguide and Optical Fibers for Novel Plasmonic Sensor Configurations. Sensors 2017, 17, 1488. [CrossRef] [PubMed]

32. Zeni, L.; Pesavento, M.; Marchetti, S.; Cennamo, N. Slab plasmonic platforms combined with Plastic Optical Fibers and Molecularly Imprinted Polymers for chemical sensing. Opt. Laser Technol. 2018, 107, 484-490. [CrossRef]

33. Arcadio, F.; Zeni, L.; Montemurro, D.; Eramo, C.; Di Ronza, S.; Perri, C.; D'Agostino, G.; Chiaretti, G.; Porto, G.; Cennamo, N. Biochemical sensing exploiting plasmonic sensors based on gold nanogratings and polymer optical fibers. Photonics Res. 2021, 9 , 1397-1408. [CrossRef]

34. Arcadio, F.; Zeni, L.; Minardo, A.; Eramo, C.; Di Ronza, S.; Perri, C.; D’Agostino, G.; Chiaretti, G.; Porto, G.; Cennamo, N. A Nanoplasmonic-Based Biosensing Approach for Wide-Range and Highly Sensitive Detection of Chemicals. Nanomaterials 2021, 11, 1961. [CrossRef]

35. Cui, M.; Xin, Y.; Song, R.; Sun, Q.; Wang, X.; Lu, D. Fluorescence sensor for bovine serum albumin detection based on the aggregation and release of CdS QDs within CMC. Cellulose 2020, 27, 1621-1633. [CrossRef]

36. Xu, X.J.; Huang, J.; Li, J.J.; Yan, J.W.; Qin, J.G.; Li, Z. A graphene oxide-based AIE biosensor with high selectivity toward bovine serum albumin. Chem. Commun. 2011, 47, 12385-12387. [CrossRef] [PubMed]

37. Kaushik, S.; Tiwari, U.K.; Deep, A.; Sinha, R.K. Two-dimensional transition metal dichalcogenides assisted biofunctionalized optical fiber SPR biosensor for efficient and rapid detection of bovine serum albumin. Sci. Rep. 2019, 9, 6987. [CrossRef]

38. Jia, K.; Khaywah, M.Y.; Li, Y.; Bijeon, J.L.; Adam, P.M.; Déturche, R.; Guelorget, B.; François, M.; Louarn, G.; Ionescu, R.E. Strong Improvements of Localized Surface Plasmon Resonance Sensitivity by Using Au/Ag Bimetallic Nanostructures Modified with Polydopamine Films. ACS Appl. Mater. Interfaces 2014, 6, 219-227. [CrossRef]

39. Pathak, A.; Parveen, S.; Gupta, B.D. Ultrasensitive, highly selective, and real-time detection of protein using functionalized CNTs as MIP platform for FOSPR-based biosensor. Nanotechnology 2017, 28, 355503. [CrossRef] [PubMed]

40. Wang, Y.; Wei, T. Surface plasmon resonance sensor chips for the recognition of bovine serum albumin via electropolymerized molecularly imprinted polymers. Chin. Chem. Lett. 2013, 24, 813-816. [CrossRef] 